\title{
Physicians' electronic health records use at home, job satisfaction, job stress and burnout
}

\author{
Michael R. Privitera*1,6, Fouad Atallah2,6, Frank Dowling ${ }^{3,6}$, Caroline Gomez-DiCesare ${ }^{4,6}$, Arthur Hengerer,5,6 ${ }^{1,5 a t i e}$ \\ Arnhart $^{5}$, Aaron Young 5 , Mark Staz ${ }^{5}$ \\ ${ }^{1}$ University of Rochester Medical Center, Department of Psychiatry, Rochester, New York, United States \\ ${ }^{2}$ Maimonides Medical Center, Department of Obstetrics and Gynecology, United States \\ ${ }^{3}$ Stony Brook University Medical Center, United States \\ ${ }^{4}$ Bassett Medical Center, United States \\ ${ }^{5}$ Federation of State Medical Boards, United States \\ ${ }^{6}$ Medical Society of the State of New York Task Force on Physician Stress and Burnout, United States
}

Received: March 30, 2018

DOI: $10.5430 /$ jha.v7n4p52
Accepted: June 4, 2018

Online Published: June 20, 2018

\begin{abstract}
Objective: To determine how electronic health record (EHR) use at home impacts physician job satisfaction, job stress and burnout.

Methods: This study looks at survey responses from 1,048 physicians in New York in 2016 to see how time spent on EHRs at home affected physician's job satisfaction, job stress and burnout.

Results: Accounting for demographic and practice values, physicians' moderately high to excessive time spent on EHRs at home did not significantly affect job satisfaction but did significantly increase their odds of experiencing job stress by $50 \%$ and burnout by $46 \%$. However, length and degree of documentation requirements and extension of work life into home by means of e-mail, completion of records and phone calls significantly correlated to decreased job satisfaction and increased job stress and likelihood of burnout.

Conclusions: Although technology allows for physicians to work on electronic devices in various locations, healthcare administrators, policy makers and physicians alike should be aware of negative implications of excessive EHR use, documentation completion, e-mails and phone calls at home. Greater attention is needed on the human factors in the delivery of care and the importance of joy in the practice of medicine. Suggestions for organizational interventions are discussed.
\end{abstract}

Key Words: Electronic medical record, Electronic health record, Burnout, Work/home boundaries, Technology acceleration, Human factors/ergonomics

\section{INTRODUCTION}

We live in the age of accelerations, where rapid changes in technology from exponential growth of processing power have led to an increase of information flow, connectivity, accountability and expectations, outstripping the ability of hu- mans to adapt. ${ }^{[1]}$ Yet, physicians, like many other professionals, are expected to adapt to the rapid changes in technology while dealing with the usual demands of being a physician and preserving a life outside of medicine. Consideration of human capabilities as well as limitations is becoming more

\footnotetext{
*Correspondence: Michael R. Privitera; Email: michael_privitera@urmc.rochester.edu; Address: University of Rochester Medical Center, Department of Psychiatry, Rochester, New York, United States.
} 
necessary in healthcare delivery leadership decisions. Applying a human factors/ergonomics (HFE) framework that considers these factors is now very relevant. HFE considers physical, cognitive and organizational ergonomics with the goal of optimizing performance while maintaining worker wellbeing. Patient safety is a product of optimal healthcare system performance. ${ }^{[2]}$

Electronic health record (EHR) effects on burnout have been well studied. ${ }^{[3,4]}$ While many of the factors leading to burnout are systemic and have been examined regarding the workplace, the psychosocial impact or the extension of work into home life afforded by technology and external expectations has not been well studied. Technological ease of access of work into the clinician's home has the potential to be another source of work-home conflict that has been associated with high stress, burnout and serious disruptions to relationships. ${ }^{[5]}$ Since clinicians are accountable for their decisions no matter what time of the day they make them, work-required vigilance gets extended for long periods of time without sufficient restorative down time.

Over half of US physicians report experiencing a great deal of stress and symptoms of burnout. ${ }^{[6-8]}$ In recent years, the percentage of physicians reporting burnout has risen $9 \%$ compared to three years previously. ${ }^{[6]}$ In addition to the personal threat to healthcare professionals themselves, there is clear evidence that chronic stress and burnout threatens healthcare delivery, quality, safety and access to care. ${ }^{[7,9,10]}$ It is important that contributing factors that decrease physicians' job satisfaction and increase job stress and burnout are identified and minimized where possible. This study looks at how physicians' time spent on EHRs at home and other extensions of the workplace into home life (e-mails, completion of records, and phone calls) may influence their job satisfaction, job stress and likelihood of burnout.

Many physicians had looked forward to using EHRs and the benefits they can offer including improved patient care and the ability to access records remotely. With federal stimulus support, EHRs became affordable and their use has been wide-spread. ${ }^{[11,12]}$ During this time period many other events occurred contemporaneously with the increase in EHR implementation: The passage of the Affordable Care Act, multiple quality metrics, Meaningful Use (MU) which was meant to serve as a universal preventive measure requiring certain data capture for every patient visit regardless of the reason, and the Triple Aim's focus on cost, quality and the patient experience. ${ }^{[13]}$ EHR vendor priority was certification for MU requirements. As a result, these requirements trumped and bypassed sufficient physician input into EHR design to improve clinical and ergonomic efficiency. Hundreds of

Published by Sciedu Press healthcare technology related businesses that interface with the EHR vendor system would then align their priorities to the EHR vendor. Additional to the above changes, the medical note content expanded to include features for billing and regulation while ultra-conservative scope of practice interpretations required clinicians to pick up more duty in the EHR system than previously done in paper-based systems. These factors have combined to create a poorly designed and inefficient product from a clinician's point of view. Approximately $85 \%$ of physicians in the U.S. use EHRs ${ }^{[3]}$ and EHRs are one of many ways that technology is changing the documentation and delivery of healthcare.

Even though EHR use has its advantages, the concern has been posed that physicians now spend a significant time in front of the computer and that time on EHRs is less rewarding that other clinical tasks. ${ }^{[4,11]}$ It is estimated that for every hour of clinical face time with a patient, 2 hours of EHR use and desk time are required. ${ }^{[4]}$ EHR and/or computerized physician order entry (CPOE) use have also been associated with lower job satisfaction, lower satisfaction with the amount of time spent on clerical tasks, greater stress and increased risk of burnout. ${ }^{[3,12]}$ EHR use has been shown to lengthen physicians' work days and extend into their home life. ${ }^{[3]}$ In a 2014 survey, over half of the clinicians stated that the amount of time spent on EMR (electronic medical record) at home was moderate, high or excessive. ${ }^{[10]}$

While research has documented negative effects of excessive EHR use and that physicians are spending time on EHR at home, less information is known on how EHR use at home affects physicians' well-being and work outcomes. This study looks to extend EHR use and other technological extensions into home and physician outcomes research by using data from a 2016 survey of physicians in New York to see how EHR use at home may affect their job satisfaction, job stress and likelihood of burnout, once accounting for several demographic and practice variables.

\section{Methods}

In 2016, physicians in New York State filled out a survey regarding practice conditions sent out by the Medical Society of the State of New York (MSSNY), including questions from the Mini Z Burnout Survey. ${ }^{[5]}$ This survey instrument helps identify major contributors to physician burnout including job satisfaction, stress, symptoms of burnout, control over workload, sufficiency of time for documentation, atmosphere of primary work area, professional value alignment with leaders and amount of time spent on the EHR at home. The survey also asked respondents to select from 16 workrelated issues (including an "other" option) that contributed to their stress level in the last year. 
Survey invitations were sent to 27,700 individuals and opened by 8,109 individuals. Of those who opened an invitation, 1,191 individuals completed the survey (15\%). This survey response rate was noted to be much higher than the average response rate to other surveys sent out by MSSNY. We excluded 59 respondents from this analysis because they were currently in training and 84 respondents who had missing or insufficient group-level data, yielding a final sample size of 1,048 physicians. The supplemental frequency and correlation of work-related issues that contributed to stress levels in the past year had an additional 4 missing responses for a sample size of 1,044 physicians. Survey response groupings were similar to Linzer's grouping methods with application of the Mini Z survey. ${ }^{[10]}$ This study was reviewed by the University of Rochester Office of Human Subject Protection and deemed exempt from further review.

\section{Results}

With regards to control and explanatory variables, approximately two-thirds $(63 \%, \mathrm{n}=660)$ of the physicians in the survey were male and on average 55.1 years old $(S D=11.3$ years). As a check on data quality, we compared the gender and age from this survey to physicians who were actively licensed to practice medicine in New York in 2016 $(n=93,951)$. Comparable to the survey data, $62 \%$ of actively licensed physicians in New York in 2016 were male (35\% female, $4 \%$ unknown) and on average 52 years old $\left(S D=14\right.$ years, $\left.\mathrm{n}_{\text {unknown }}=2,067\right)$. Forty percent $(\mathrm{n}=423)$ of physicians worked in an academic setting and on average worked 54.5 hours per week $(S D=18.7$ hours) (see Table 1$)$.

Slightly more than half of the physicians $(52 \%, \mathrm{n}=541)$ indicated their control over their workload was poor or marginal, while the remainder $(48 \%, \mathrm{n}=507)$ indicated their control of their workload was optimal, good or satisfactory. In response to the statement, "My professional values are well aligned with those of my department leaders", $40 \%(n=420)$ of physicians strongly agreed or agreed and $60 \%(n=628)$ either strongly disagreed, disagreed or neither agreed or disagreed. When asked which best describes the atmosphere in your primary work area, 29\% $(n=303)$ chose hectic, chaotic and $71 \%(n=745)$ chose either busy, but reasonable or calm. Just under one-third $(32 \%, \mathrm{n}=333)$ of physicians thought their sufficiency for time documentation was either optimal, good or satisfactory, while $68 \%(n=715)$ of physicians thought their time documentation was either poor or marginal. Approximately half of physicians $(50 \%, \mathrm{n}=527)$ thought the amount of time they spent on the EHR at home was either excessive or moderately high while the other half $(50 \%$, $\mathrm{n}=521$ ) thought it was satisfactory, modest or minimal/none.
Table 1. Physician characteristics from MSSNY physician stress and burnout survey, 2016

\begin{tabular}{|c|c|c|}
\hline & Number & Percent \\
\hline \multicolumn{3}{|l|}{ Gender } \\
\hline Male & 660 & $63.0 \%$ \\
\hline Female & 388 & $37.0 \%$ \\
\hline Age, mean $(S D)$, years & 55.1 & 11.3 \\
\hline \multicolumn{3}{|l|}{ Academic Setting } \\
\hline Yes & 423 & $40.4 \%$ \\
\hline No & 625 & $59.6 \%$ \\
\hline Work Hours Per Week, mean $(S D)$ & 54.5 & 18.7 \\
\hline \multicolumn{3}{|l|}{ Workload Control } \\
\hline Optimal/Good/Satisfactory & 507 & $48.4 \%$ \\
\hline Poor/Marginal & 541 & $51.6 \%$ \\
\hline \multicolumn{3}{|l|}{ Aligned Values } \\
\hline Strongly Agree/Agree & 420 & $40.1 \%$ \\
\hline Strongly Disagree/Disagree/Neither & 628 & $59.9 \%$ \\
\hline \multicolumn{3}{|l|}{ Work Environment } \\
\hline Hectic, Chaotic & 303 & $28.9 \%$ \\
\hline Busy, but Reasonable/Calm & 745 & $71.1 \%$ \\
\hline \multicolumn{3}{|l|}{ Time Documentation } \\
\hline Optimal/Good/Satisfactory & 333 & $31.8 \%$ \\
\hline Poor/Marginal & 715 & $68.2 \%$ \\
\hline \multicolumn{3}{|l|}{ EHR at Home } \\
\hline Excessive/Moderately High & 527 & $50.3 \%$ \\
\hline Satisfactory/Modest/Minimal/None & 521 & $49.7 \%$ \\
\hline \multicolumn{3}{|l|}{ Job Satisfaction } \\
\hline Strongly Agree/Agree & 535 & $51.0 \%$ \\
\hline Strongly Disagree/Disagree/Neutral & 513 & $49.0 \%$ \\
\hline \multicolumn{3}{|l|}{ Job Stress } \\
\hline Strongly Agree/Agree & 718 & $68.5 \%$ \\
\hline Strongly Disagree/Disagree/Neutral & 330 & $31.5 \%$ \\
\hline \multicolumn{3}{|l|}{ Burnout } \\
\hline Yes & 590 & $56.3 \%$ \\
\hline No & 458 & $43.7 \%$ \\
\hline $\mathrm{n}=1,048$ & & \\
\hline
\end{tabular}

With regards to the dependent variables in the study, in response to the statement, "Overall, I am satisfied with my current job", 51\% (n = 535) of physicians strongly agreed or agreed, while $49 \%(n=513)$ either strongly disagreed, disagreed or were neutral. When asked if they felt a great deal of stress because of their job, $69 \%$ $(n=718)$ of physicians strongly agreed or agreed and $31 \%$ $(n=330)$ either strongly disagreed, disagreed or were neutral. A little over half $(56 \%, n=590)$ of physicians were identified as burned-out and selected one of the following responses: "I am definitely burning out and have one or more symptoms of burnout, e.g., emotional exhaustion", "The symptoms of burnout that I am experiencing won't go away. I think about 
work frustrations a lot" or "I feel completely burned out. completion of records, phone calls). Eight of the top 10 I am at the point where I may need to seek help". Physicians who were not identified as burned-out $(44 \%, \mathrm{n}=458)$ selected one of these following responses: "I enjoy my work. I have no symptoms of burnout" or "I am under stress, and don't always have as much energy as I did, but I don't feel burned out."

Table 2 summarizes the rank order of the top 10 work-related issues that contributed to physicians' stress levels during the past year. The most frequently identified work-related stressor was the length and degree of documentation requirements $(66 \%, \mathrm{n}=694)$, followed by $59 \%(\mathrm{n}=615)$ of physicians $(80 \%)$ were organizational/systemic in origin.

Table 3 shows how the top 10 work-related issues that contributed to physicians' stress levels during the past year are correlated with job satisfaction, job stress and burnout. Length and degree of documentation requirements is negatively correlated with job satisfaction $(r=-0.122, p<.001)$ and positively correlated with job stress $(r=0.205, p<.001)$ and burnout $(r=0.200, p<.001)$. Extension of workplace into home life is negatively correlated with job satisfaction $(r=-0.155, p<.001)$ and positively correlated with job stress $(r=0.252, p<.001)$ and burnout $(r=0.230, p<.001)$. who cited the extension of workplace into home life (e-mail,

Table 2. Top 10 work-related issues that contributed to stress levels in past year

\begin{tabular}{llll}
\hline Rank & & Frequency & Percent \\
\hline 1 & Length and degree of documentation requirements & 694 & $66.5 \%$ \\
2 & Extension of workplace into home life (E-mail, completion of records, phone calls) & 615 & $58.9 \%$ \\
3 & Prior authorizations for medications/procedures/admissions & 579 & $55.5 \%$ \\
4 & EMR functionality problems & 546 & $52.3 \%$ \\
5 & Dealing with difficult patients & 545 & $52.2 \%$ \\
6 & CMS/state/federal laws and regulations & 477 & $45.7 \%$ \\
7 & Lack of voice in being able to decide what good care is & 414 & $39.7 \%$ \\
8 & Hospital/insurance company imposed quality metrics & 399 & $38.2 \%$ \\
9 & Requirement for increased CME/ Maintenance of Certification & 337 & $32.3 \%$ \\
10 & Dealing with difficult colleagues & 323 & $30.9 \%$ \\
$\mathrm{n}=1,044 ;$ Missing = & & \\
\hline
\end{tabular}

Table 3. Correlation of top 10 work-related issues that contributed to stress levels in past year, job satisfaction, job stress and burnout

\begin{tabular}{llll}
\hline Work-Related Issues & Job Satisfaction & Job Stress & Burnout \\
\hline Length and degree of documentation requirements & $-0.122^{* * *}$ & $0.205^{* * *}$ & $0.200^{* * *}$ \\
Extension of workplace into home life & $-0.155^{* * *}$ & $0.252^{* * *}$ & $0.230^{* * *}$ \\
Prior authorizations for medications/procedures/admissions & -0.048 & $0.107^{* * *}$ & $0.061^{*}$ \\
EMR functionality problems & $-0.137^{* * *}$ & $0.114^{* * *}$ & $0.114^{* * *}$ \\
Dealing with difficult patients & $-0.062^{*}$ & $0.158^{* * *}$ & $0.209^{* * *}$ \\
CMS/state/federal laws and regulations & $-0.064^{*}$ & $0.112^{* * *}$ & $0.106^{* * *}$ \\
Lack of voice in being able to decide what good care is & $-0.272^{* * *}$ & $0.238^{* * *}$ & $0.249^{* * *}$ \\
Hospital/insurance company imposed quality metrics & $-0.071^{*}$ & $0.117^{* * *}$ & $0.149^{* * *}$ \\
Requirement for increased CME/ Maintenance of Certification & -0.051 & $0.103^{* * *}$ & $0.135^{* * *}$ \\
Dealing with difficult colleagues & $-0.088^{* *}$ & $0.098^{* *}$ & $0.111^{* * *}$ \\
$\mathrm{n}=1,044 ;$ Missing $=4$ & & & \\
\hline Note. ${ }^{*} p<.05,{ }^{* * *} p<.01,{ }^{* * *} p<.001$ & & &
\end{tabular}




\subsection{Binary-logit regression results for job satisfaction}

Accounting for all other variables, physicians with greater workload control and aligned values with departmental leaders experience an estimated increase in odds of being satisfied with their job by $3.57(p<.001)$ and $2.66(p<.001)$ respectively, compared to physicians who do not have workload control or aligned values with their departmental leaders. Comparatively, physicians working in a hectic, chaotic work atmosphere have an estimated decreased odds in job satis- faction by $0.69(p<.05)$ compared to physicians working in a busy but reasonable or calm environment. Physicians having poor to marginal amount of time for documentation have estimated decreased odds in job satisfaction by 0.65 $(p<.05)$, compared to those who have optimal, good or satisfactory amount of time for documentation. Amount of time spent on EHR at home did not significantly affect physicians' job satisfaction after accounting for other demographic and practice variables (see Table 4).

Table 4. Binary-logit regression estimating likelihood of job satisfaction, job stress \& burnout

\begin{tabular}{|c|c|c|c|c|c|c|}
\hline & \multicolumn{2}{|c|}{ Job Satisfaction } & \multicolumn{2}{|c|}{ Job Stress } & \multicolumn{2}{|c|}{ Burnout } \\
\hline & OR & Std. Err & OR & Std. Err. & OR & Std. Err. \\
\hline Male & 0.957 & 0.150 & 0.793 & 0.166 & 0.807 & 0.158 \\
\hline Age & 1.006 & 0.007 & $0.972^{* * *}$ & 0.007 & $0.966^{* * *}$ & 0.007 \\
\hline Academic Setting & 1.303 & 0.145 & $0.710^{*}$ & 0.158 & $0.505^{* * *}$ & 0.155 \\
\hline Worked Hours/Week & 1.000 & 0.004 & $1.012^{*}$ & 0.004 & $1.008^{*}$ & 0.004 \\
\hline Workload Control & $3.574^{* * *}$ & 0.152 & $0.297^{* * *}$ & 0.170 & $0.236^{* * *}$ & 0.159 \\
\hline Aligned Values & $2.659^{* * *}$ & 0.147 & $0.702^{*}$ & 0.157 & $0.664^{* *}$ & 0.154 \\
\hline Hectic Environment & $0.689^{*}$ & 0.167 & $2.234^{* * *}$ & 0.214 & $1.953^{* * *}$ & 0.183 \\
\hline Poor Time Doc. & $0.647^{*}$ & 0.174 & $1.795^{* * *}$ & 0.172 & $1.978^{* * *}$ & 0.175 \\
\hline EHR at Home & 0.820 & 0.154 & $1.500^{*}$ & 0.166 & $1.455^{*}$ & 0.160 \\
\hline $\mathrm{n}$ & 1,048 & & 1,048 & & 1,048 & \\
\hline
\end{tabular}

Note. ${ }^{*} p<.05,{ }^{* *} p<.01,{ }^{* * *} p<.001$

\subsection{Binary-logit regression results for job stress}

Greater workload control decreases the odds that physicians will experience job stress by an estimated $0.30(p<.001)$ compared to physicians who do not have workload control. Physicians who have aligned values with departmental leaders had decreased odds that they will experience job stress by an estimated $0.70(p<.05)$ compared with those not so aligned values with their departmental leaders. Physicians working in a hectic, chaotic work atmosphere have an estimated increased odds that they will experience job stress by $2.23(p<.001)$ compared to physicians working in a busy but reasonable or calm environment. Those having poor to marginal amount of time for documentation have an estimated increased odds that they will experience job stress by $1.80(p<.001)$ compared to those with optimal, good or satisfactory amount of time for documentation. Physicians who spend an excessive or moderately high amount of time on an EHR at home are at an estimated increased odds of experiencing job stress by $1.50(p<.05)$ compared to physicians who spend a satisfactory, modest or minimal/no amount of time on EHR at home. Stated another way, spending an excessive or moderately high amount of time on the EHR at home results in a 50\% increase in the odds of the physicians experiencing job stress (see Table 4).

\subsection{Binary-logit regression results for burnout}

The direction and significance of workload control, aligned values with departmental leaders, working in a hectic environment, poor time documentation and time spent on the EHR at home for physician burnout is similar to job stress. Physicians with greater workload control are at an estimated decreased odds that they will experience physician burnout by $0.24(p<.001)$. Those with aligned values with departmental leaders are at an estimated decreased odds that they will experience physician burnout by $0.66(p<.01)$ compared to physicians who do not. Physicians working in a hectic, chaotic work atmosphere are at an estimated increased odds that they will experience burnout by 1.95 $(p<.001)$ compared to physicians working in a busy but reasonable or calm environment. Those having poor to marginal amount of time for documentation are at an estimated increased odds that they will experience burnout by 1.98 $(p<.001)$ compared to or have optimal, good or satisfactory amount of time for documentation. Physicians who spend an excessive or moderately high amount of time on the EHR at home are at an estimated increased odds of experiencing physician burnout by an estimated 1.46 $(p<.05)$ or $46 \%$ compared to physicians who spend a satisfactory, modest or minimal/no amount of time on EHR at home (see Table 4). 


\section{Discussion AND CONCLUSIONS}

Our findings help extend stress and burnout research by identifying that excessive or moderately high EHR use at home, not necessarily just EHR use and other computer-based tasks in the traditional workplace, can increase the likelihood of physician stress and burnout. ${ }^{[3,6,12]}$ We found that in a sample of New York physicians, excessive or moderately high amounts of time using EHRs at home resulted in an estimated $50 \%$ increase in the odds of experiencing job stress and a $46 \%$ increase in the odds of experiencing burnout, after controlling for several demographic and practice factors. Over half of the respondents identified that length and degree of documentation requirements and extension of workplace into home life were work-related issues that contributed to their stress and significantly decreased job satisfaction, increased job stress and burnout. Additionally, lack of workload control and aligned values, insufficient time for documentation and a hectic, chaotic work environment all contributed to lower odds of physicians being satisfied at their job and higher odds of experiencing job stress and burnout.

We failed to find in a binary-logit regression that excessive or moderately high amounts of time using EHRs at home significantly influenced physicians' job satisfaction, though there was significant correlation of decreased job satisfaction with greater documentation requirements and an extension of the workplace into home life by means of e-mail, completion of records and phone calls. Given these findings, it could be that the control and autonomy derived by the flexibility of EHR use at home may contribute to improved job satisfaction in enough people to offset the statistical effect because the clinician could at least physically get home despite excessive documentation requirements and poor EHR functionality. Conversely, working on EHR at home could be perceived as negative when it infringes upon home-life, especially when perceived as "excessive", and may be indirectly measuring more work-home conflict, as other extensions of workplace into home as phone calls, e-mails and completion of documentation at home are detrimental. Whether EHR use at home is reflecting work flexibility or perceived negatively, the common factor is that poor EHR design slows work efficiency, increasing the likelihood of not being finished with documentation during work hours. Since many clinicians are salaried, these extra hours do not create an extra cost to the institution, and therefore come without managerial pressures to control the amount of work done at home. More research should be conducted to see if and how EHR use at home and other boundary issues between work and home impact physicians' job satisfaction, quality of life, sustainability of practice and life satisfaction.

Our findings underscore the importance of addressing sys- temic issues in the practice of medicine. While individual interventions to increase job satisfaction and reduce stress and burnout may be partially helpful, more emphasis must be placed on organizationally-based interventions as they represent the preponderance of significant stressors on physicians. Since technological advances afford 24/7 availability of clinicians to their jobs, it will take progressive and integrative-thinking ${ }^{[14]}$ from decision-makers to implement policy, guidelines and cultural change to respect clinician off-time as an essential part of the sustainable safe practice of medicine. Technology and high EHR use, however, are not the only factors to blame for increasing rates of physician job stress and burnout. Focused efforts are needed to foster change in the physician culture of endurance and hyper-expectation that is perpetuated internally and externally in medicine to the personal detriment of clinicians, their families and the patients they serve. ${ }^{[15,16]}$ Blurring of the boundaries between work and home must be reduced and eliminated wherever possible. Improving relationships between clinicians and administrators will improve two-way listening to the needs of both groups which could synergize more rapid culture and policy change. More attention to the human factors associated with the delivery of care must be taught to leaders who make decisions about clinicians subordinate to them. The importance of life outside of medicine is underappreciated as to its restorative effect for sustainable safe practice. Work must be contained at work as much as possible. Research in Self Determination Theory in work-related outcomes shows three basic psychological needs of autonomy, competence and relatedness are essential. Frustration of these have shown work related outcomes of higher levels of emotional exhaustion, energy depletion, dysfunction, illness, turnover intention and absenteeism. ${ }^{[17]}$

Improving the alignment in values between physicians and their leaders can be helped by bottom up input into decisions that affect the clinical life of the physician, as has been modeled by participatory management that improves job satisfaction. ${ }^{[18-20]}$ Participatory management is a process in which influence is shared among hierarchical unequals, balancing involvement of leaders and their subordinates in informationprocessing, problem-solving and decision-making where possible.

Our study further highlights the opportunity and necessity for a shared accountability of vendors, regulators, healthcare industry and other healthcare stakeholders to the wellbeing of clinicians who take care of our patients. ${ }^{[21]}$ The Triple Aim has been a framework for healthcare delivery on the metrics of improving the patient experience, improving population health and decreasing costs. ${ }^{[13]}$ The Quadruple Aim expands the Triple Aim to add improving the experience 
of providing care as a key metric in improving healthcare delivery. ${ }^{[22,23]}$ This expanded approach underlies the human factors ${ }^{[24]}$ involved in the experience of providing care and care delivery in general. The Quadruple Aim supports the shared accountability approach to the wellbeing of clinicians and helps undo a current presumption of unlimited clinician workload capabilities. A framework of limitations in clinician resource to achieve a goal then forces solutions that optimize what is truly important in the care of patients. The amount of documentation, whether in the workplace or at home, needs to be re-examined and strategically reduced by institutions and regulators to be manageable and truly meaningful for the optimal care of the patient. ${ }^{[25,26]}$

\section{Limitations}

There are limitations to our study. Results are based upon self-report and individual subjective perceptions (for example, the variation in how individuals define "excessive" time of EHR use at home). However, the term "excessive" allows for the inclusion of the users' perspective of frustration, effort and time which are valuable components of workload assessment. ${ }^{[12]}$ Results are limited to physicians licensed within New York, however, the database is from a representative cross-section of New York physicians from a diverse population including inner city, rural, female, minority, academic, nonacademic, private and employed physicians.

\section{ACKNOWLEDGEMENTS}

We would like to thank all the Medical Society of the State of New York Task Force on Physician Stress and Burnout and Task Force members as well as MSSNY staff for their assistance in delivery and data management of the survey.

\section{IRB APPROVAL}

University of Rochester Office of Human Subject Protection, deemed exempt.

\section{CONFLicts OF InTEREST Disclosure}

The authors declare they have no conflicts of interest.

\section{REFERENCES}

[1] Friedman T. Thank you for being Late. An optimists guide to thriving in and age of accelerations. New York: Farrar, Straus \& Giroux; 2016.

[2] International Ergonomics Association. Available from: www.iea.cc

[3] Shanafelt TD, Dyrbye LN, Sinsky C, et al. Relationship between clerical burden and characteristics of the electronic environment with physician burnout and professional satisfaction. Mayo Clinic Proceedings. 2016; 91(7): 836-848. PMid: 27313121. https: //doi.org/10.1016/j.mayocp.2016.05.007

[4] Sinsky C, Colligan L, Li L, et al. Allocation of physician time in ambulatory practice: a time and motion study in 4 specialties. Ann Intern Med. 2016; 165(11): 753-760. PMid: 27595430 https://doi.org/10.7326/M16-0961

[5] Dyrbye LN, Sotile W, Boone S, et al. A survey of us physicians and their partners regarding the impact of work-home conflict. J. Gen Intern Med. 2014; 29(1): 155-161. PMid: 24043567. https: //doi.org/10.1007/s11606-013-2581-3

[6] Shanafelt TD, Hasan O, Dyrbye LN, et al. Changes in burnout and satisfaction with work-life balance in physicians and the general us working population between 2011 and 2014. Mayo Clinic Proceedings. 2015; 90(12): 1600-1613. PMid: 26653297. https : //doi.org/10.1016/j.mayocp. 2015.08.023

[7] Shanafelt TD, Dyrbye LN, West CP. Addressing physician burnout: the way forward. JAMA. 2017; 317(9): 901-902. https://doi.or g/10.1001/jama. 2017.0076

[8] Linzer M, Manwell LB, Williams ES, et al. Working conditions in primary care: physician reactions and care quality. Ann Intern Med. 2009; 151(1): 28-36. PMid: 19581644. https://doi.org/10.7 326/0003-4819-151-1-200907070-00006

[9] Friedberg MW, Chen PG, Van Busum KR, et al. Factors affecting physician professional satisfaction and their implications for patient care, health systems, and health policy. Rand Health Quarterly. Santa
Monica, CA: RAND Corporation; 2013. Available from: https: //www.rand.org/pubs/research_reports/RR439.html

[10] Linzer M, Poplau S, Babbott S, et al. Worklife and wellness in academic general internal medicine: results from a national survey. Journal of General Internal Medicine. 2016; 31(9): 1-7. PMid: 27138425. https://doi.org/10.1007/s11606-016-3720-4

[11] Wachter R. The Digital Doctor: Hope hype and harm at the dawn of medicine's computer age. New York, NY: McGraw-Hill; 2015.

[12] Babbott S, Manwell LB, Brown R, et al. Electronic medical records and physician stress in primary care: results from the MEMO Study. Journal of the American Medical Informatics Association. 2014; 21(1): e100-e106. PMid: 24005796. https://doi.org/10.113 6/amiajnl-2013-001875

[13] Berwick DM, Nolan TW, Whittington J. The Triple Aim: care, health, and cost. Health Aff (Millwood). 2008; 27(3): 759-769. PMid: 18474969. https://doi.org/10.1377/hlthaff .27.3.759

[14] Martin R. How successful leaders think. Harvard Business Review. 2007; 60-67. PMid: 17580648.

[15] Epstein RM, Privitera MR. Doing something about physician burnout. Lancet. 2016; 388(10057): 2216-2217. https://doi.org/10.1 016/S0140-6736(16) 31332-0

[16] Dzau VJ, Kirch DG, Nasca TJ. To care is human - collectively confronting the clinician burnout crisis. The New England Journal of Medicine. 2018; 378(4): 312-314. PMid: 29365296. https: //doi.org/10.1056/NEJMp1715127

[17] Olafsen AH, Niemiec CP, Halvari H, et al. On the dark side of work: A longitudinal analysis using self-determination theory. European Journal of Work and Organizational Psychology. 2017; 26(2): 275 285. https://doi .org/10.1080/1359432X. 2016.1257611

[18] Locke EA, Schweiger DM. Participation in decision-making: One more look. In BM Staw (Ed), New directions in organizational behavior. Greenwich CT: JAI Press; 1979. 265-339 p. 
[19] Wagner JA. Participations effects on performance and satisfaction: A reconsideration of research evidence. Academy of Management Review. 1994; 19: 312-330. https://doi.org/10.5465/amr.19 94.9410210753

[20] Kim S. Participative management and job satisfaction: lessons for management leadership. Public Administration Review. 2002; 62(2): 231-241. https://doi.org/10.1111/0033-3352.00173

[21] Sinsky CA, Privitera MR. Creating a "manageable cockpit" for clinicians: a shared responsibility. JAMA IM. 2018; 178(6): 741-742.

[22] Bodenheimer T, Sinsky C. From triple to quadruple aim: care of the patient requires care of the provider. Ann Fam Med. 2014; 12(6): 573576. PMid: 25384822. https://doi.org/10.1370/afm.1713
[23] Sikka R, Morath JM, Leape L. The Quadruple Aim: care, health, cost and meaning in work. BMJ Qual Saf. 2015; 24(10): 608-610. PMid: 26038586. https://doi .org/10.1136/bmjqs-2015-004160

[24] Carayon P, Xie A, Kianfar S. Human factors and ergonomics as a patient safety practice. BMJ. Qual. Saf. 2014; 23: 196-205. PMid: 23813211. https://doi.org/10.1136/bmjqs-2013-001812

[25] Berwick DM, Loehrer S, Gunther-Murphy C. Breaking the rules for better care. JAMA. 2017; 317(21): 2161-2162. PMid: 28448652. https://doi.org/10.1001/jama.2017.4703

[26] Erickson SM, Rockwern B, Koltov M, et al. Putting patients first by reducing administrative tasks in healthcare: a position paper of the american college of physicians. Ann Intern Med. 2017; 166: 659-661. PMid: 28346948. https ://doi .org/10.7326/M16-2697 